\title{
Pollination and biological control research: are we neglecting two billion smallholders
}

\author{
Peter R Steward ${ }^{1 *}$, Gorm Shackelford ${ }^{1}$, Luísa G Carvalheiro ${ }^{1,2}$, Tim G Benton ${ }^{1}$, Lucas A Garibaldi ${ }^{3}$ and Steven M Sait ${ }^{1}$
}

\begin{abstract}
Food insecurity is a major world problem, with ca. 870 million people in the world being chronically undernourished. Most of these people live in tropical, developing regions and rely on smallholder farming for food security. Solving the problem of food insecurity is thought to depend, in part, on managing ecosystem services, such as the pollination of crops and the biological control of crop pests, to enhance or maintain food production. Our knowledge regarding regulating ecosystem services in smallholder-farmed (or dualistic) landscapes is limited and whilst pollination has been the focus of considerable research, the provision of natural enemy services, important for every crop worldwide, has been relatively neglected. In order to assess whether ecosystem-service research adequately represents smallholder-farmed landscapes, whilst also considering climatic region and national economic status, we examined the constituent studies of recent quantitative reviews relevant to biological control and pollination. No regulating ecosystem service meta-analysis, to our knowledge, has focussed on smallholder agriculture despite its importance to billions of peoples' local food security. We found that whilst smallholdings contributed $16 \%$ of global farmland area and $83 \%$ of the global agricultural population (estimated using Food and Agriculture Organisation's (FAO's) World Census of Agriculture 2000) only 22 of 190 studies (12\%) overall, came from smallholder-farmed landscapes. These smallholder studies mostly concerned coffee production (16 studies). Individual reviews of biological control were significantly and strongly biased towards data from large-scale farming in temperate regions. In contrast, pollination reviews included more smallholder studies and were more balanced for climate regions. The high diversity of smallholder-farmed landscapes implies that more research will be needed to understand them compared to large-scale landscapes, but we found far more research from the latter. We highlight that these skews in research effort have implications for sustainable intensification and the food security of billions in the developing world. In particular, we urge for balance in future ecosystem-services research and synthesis by greater consideration of a diverse range of smallholder-farmed landscapes in Africa and continental Asia.
\end{abstract}

Keywords: Biological control, Ecosystem service, Sustainable intensification, Smallholder, Pollination, Food security

\section{Background}

Global food insecurity is receiving increasing attention from researchers and policy makers [1-5]. An increasing human population and rising demand for more varied, high-quality diets is placing pressure on agro-ecosystems and biodiversity across the globe $[1,2,4]$. To prevent widespread food insecurity arising from the expected increase in human population size, predictions suggest that agricultural land will need to increase crop production by $60 \%$ or more by 2050 [6]. There are around 870 million hungry people today, nearly all of whom (98\%) live in developing

\footnotetext{
* Correspondence: bsprs@leeds.ac.uk

'Africa College and School of Biology, University of Leeds, Leeds LS2 9JT, UK Full list of author information is available at the end of the article
}

countries and half of them are from smallholder households $[7,8]$. As we currently produce enough calories to feed the world $[7,9]$ yet still have hunger, producing additional food in food secure areas will not solve global food insecurity alone [5]. Furthermore, the long-term sustainability of the industrial intensification of agriculture (high inputs, low crop and landscape diversity) has been questioned $[10,11]$. Where industrial agriculture exists it is often associated with soil degradation and even desertification in arid regions [2], thus, in the future, we may suffer declining production in some currently productive areas. On-going industrial intensification of agriculture, typically in developing nations, is linked to negative social and economic impacts, including poverty and loss of local 
food security $[12,13]$. Sustainable intensification, the pursuit of higher or more sustainable yields with fewer negative consequences for the environment [1], is the conceptual solution to reducing global food insecurity and meeting future food demands, and it includes the management of ecosystem services (ecological intensification) [1,2,5]. In this review, we examine how much ecosystem service research is derived from developing nations, tropical climates and smallholder farming landscapes, where local food security is at stake.

\section{Smallholder-farmed landscapes}

Smallholder farming is a major source of food production and income in many countries $[14,15]$ and for the global rural population in general. Global estimates suggest there are 2.1 to 2.5 billion people involved in farming smallholdings and 500 million smallholdings, mostly in developing nations [16,17] (Additional file 1: Table S1). The majority of the population growth forecast for 2050 will occur in sub-Saharan Africa and South Asia [18] (Additional file 2: Figure S1), where food insecurity is currently rife and more than a third of agricultural land is composed of smallholdings [7] (Additional file 1: Table S1). Thus, ensuring that sustainable intensification benefits the world's undernourished population living in developing countries, particularly those that live in smallholder households, would promote global food security and poverty reduction [19].

There is no single definition of a smallholding, but the common understanding is that the unit of land management is small. Several reports arbitrarily use a definition of two hectares or less $[14,15,20]$ but larger holdings (for example, three to five hectares) will still create very complex landscapes compared to large-scale farming. Smallholderfarmed landscapes are, therefore, greatly sub-divided and potentially have a high diversity of crops at relatively small spatial scales (Figure 1A). The higher potential for smallscale intermixing of crop and non-crop habitats (due to landscape configuration not composition) means that in a smallholder-farmed landscape the average distance of a crop-plant to a "natural" area that could enhance ecosystem service delivery can be much shorter than in a large-

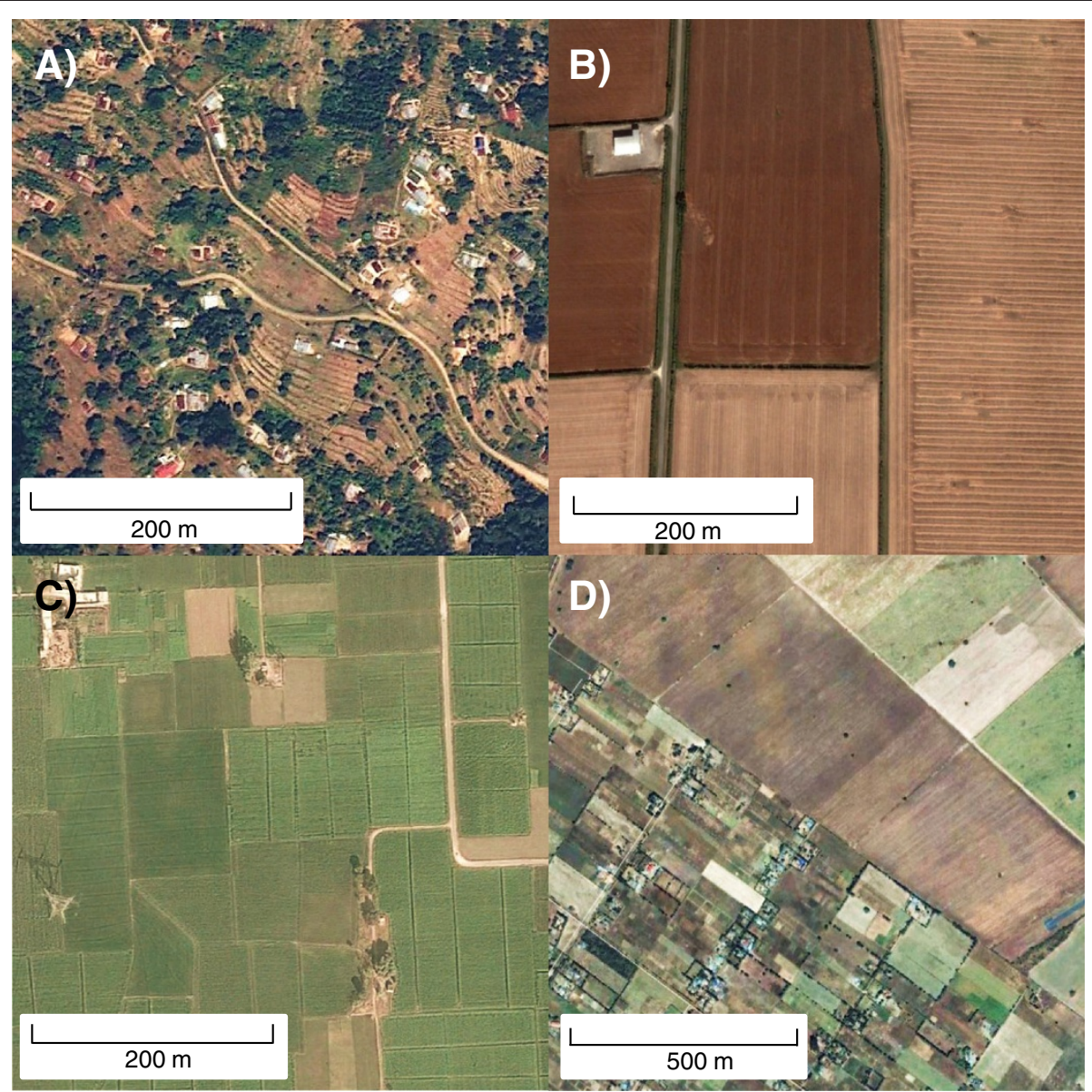

Figure 1 Examples of farming landscapes. A) Locally complex upland smallholdings, Taita, Kenya; B) Large-scale commercial farming, Norfolk, UK; C) Locally simple lowland smallholdings, Punjab, India; D) Dualistic farming with smallholdings and large-scale commercial farming, Nakuru, Kenya. 
scale farming landscape. As smallholder-farmed landscapes can be highly heterogeneous within and between landscapes (Figure 1), there are a variety of such landscapes that could be described as smallholder. For example, they can be commercial or subsistence, polycultural or monocultural, and with high or low input (Additional file 3: Figure S2). Smallholdings can merge together to form an extensive area of contiguous agriculture or they can be isolated patches surrounded by other land-uses or natural habitats.

\section{Ecological intensification and regulating ecosystem services of pollination and biological control}

The landscape provides a range of natural resources that are valuable to people. In an analogy with economics, natural "capital" (such as soils and forests) provides ecosystem services (ES) as flows (or interest) of value. These include food, forage, fibre and fuel in the case of forests, and nutrients, water and carbon storage in the case of soils. ES are broadly separable into four categories: provisioning services (food, fuel, water), regulating services (carbon storage regulates climate, plant cover regulates flood risk), supporting services (soil microbes support nutrient cycles and aid food production) and cultural services (for example, recreational, spiritual and educational values of a landscape). Pollination of crops and pest control, by natural enemies of crop pests, are regulating ecosystem services that contribute to food production. The notion of enhancing ES to increase crop yield (rather than using pesticides, fertilisers or other intensive agricultural practices) is known as "ecological intensification" [21]. It is well-established that insufficient pollination and biological control services can limit crop production when other factors such as soil nutrients and water are sufficient [21]. Evidence is now emerging to support the theory that pollination and biological control respond to similar drivers, such as floral resources and landscape structure [22-24], and it is therefore logical to consider them together.

Recent quantitative reviews [for example, 25-28] have investigated factors that affect pollination and biological control services or providing species, such as the influence of landscape complexity and management practices, and have shown that variability in ES provision is likely to be context dependent [25-28]. For example, the diversity of both pollinators and natural enemies seems to be higher in complex agro-ecosystems, and pollination services are generally stronger and more stable on farms near natural habitats $[28,29]$. The results of quantitative reviews have a key role to play in synthesising the evidence and parameterising models that can predict ES provisioning (such as InVEST, see [30]), and therefore they contribute to the design of sustainable farming landscapes and the policy interventions that bring them about. The extent to which the body of the work synthesised in such reviews can suggest management interventions across a range of agricultural systems clearly depends on the range and representativeness of the studies included. Geographical biases have recently been demonstrated in reviews relevant to pollination ecology suggesting our understanding of pollination is poor in developing regions such as sub-Saharan Africa [31]. We build on these findings, with regards to food security, by focussing on regulating ES research relevant to crop productivity and by evaluation of the farming landscape where data were collected, particularly with regard to smallholdings. In this study we specifically ask if the constituent studies of recent reviews relevant to agricultural pollination and biological control adequately represent farming landscapes (smallholder-farmed vs. large-scale farming), global biomes, regions (as defined by the World Bank), and national income statuses.

\section{Methods}

In May 2013, we used a Web of Science topic search for "[landscape OR disturbance OR diversity OR crop yield OR fruit set OR food production] AND [pollinat* OR natural enem* OR biological control OR CBC OR pest control] AND [meta-analysis OR review]" (Year >2005) to find recent quantitative reviews relevant to crop pollination and biological control (note CBC means conservation biological control). Reviews were excluded (Additional file 4: Table S2) if they had a regional focus, were relevant only to a specific crop, did not use meta-analysis or quantify/ model a trend or pattern, or used few agricultural studies (less than 50\%). Any additional reviews relevant to pollination and biological control referenced in selected reviews were also included in the screening process. The agricultural studies used in each review (Additional file 5: Table S3) were selected for further analysis $(n=190)$. We excluded studies with no focus on crops $(n=63)$ (for example, those conducted in natural habitats), no field component (those conducted in labs or greenhouses), or those conducted in plantation forests. The selected reviews and the studies therein did not necessarily consider ES impacts on crop yields directly. Often it was the response of ES providers that was the focus of a study, with no or limited quantification of impacts on food production. However, some reviews did link ES providers to yield, such as Garibaldi et al. (2013), which linked wild pollinators to fruit-set. Thus, when we refer to "pollination" reviews or studies, these are relevant to pollination, but they did not necessarily directly quantify it, and might instead have focused on the abundance and diversity of pollinators. The same is true for "biological control" reviews or studies, which did not necessarily directly estimate pest suppression, but might instead have used proxies such as natural enemy abundance and diversity. 
Studies were manually assigned to a farming landscape (smallholder or large-scale; Table 1) based on descriptions in the publication, satellite imagery from BingMaps [32] and GoogleMaps [33] and, in some cases, direct correspondence from authors. It is possible that some landscapes may have changed since the date of fieldwork in a study, but we found no discordance between author descriptions and satellite imagery. It should be noted that the relative (\%) composition detailed in Table 1 classifies landscapes from land that is under temporary arable agriculture and (or) permanent cropland. These comprise crops that are sown or planted once and crops that are not replanted after each harvest, such as cocoa, coffee and rubber (but not timber).

From an ES perspective we believe that a 2-ha maximum field size (as often used in United Nations Environment Programme (UNEP) or Food and Agriculture Organisation (FAO) reports) was too small to define smallholder-farmed landscapes because areas with many fields of 3 ha still have high local and landscape complexity. Therefore, we used a 3-ha maximum field size, which gave conservative results (given our a priori assumption that smallholdings will be underrepresented) that slightly over-estimated the number of studies from smallholderfarmed landscapes (considering our expected values are derived from [17] using a maximum field size of 2 ha). Landscapes with $\geq 33 \%$ of (arable and permanent) cropland areas composed of fields $<3$ ha and $<33 \%$ of cropland areas composed of fields $>5$ ha were considered to be smallholder-farmed landscapes. Landscapes with $\geq 33 \%$ of cropland areas composed of fields $<3$ ha and $\geq 33 \%$ of cropland areas composed of fields $>10$ ha were considered to be dualistic landscapes. To provide a sufficient contrast to smallholder or dualistic landscapes, large-scale landscapes were defined as having $\leq 33 \%$ of cropland areas composed of fields $<5$ ha and $\geq 33 \%$ of cropland areas composed of fields $>10$ ha. If a landscape had large areas under a single management, but small field sizes, such as a large-scale commercial orchard subdivided into small sub-units, these were classified as large-scale. Author descriptions of the farming system were particularly important in the characterisation of orchard and plantation

Table 1 Criteria used to classify farming landscape

\begin{tabular}{llll}
\hline \multicolumn{4}{c}{ Field size } \\
\hline Farming landscape & 3 ha & $\geq 5$ ha & $\geq 10$ ha \\
Smallholder & $\geq 33 \%$ & $\leq 33 \%$ & - \\
Dualistic & $\geq 33 \%$ & - & $\geq 33 \%$ \\
Large-scale & - & $\leq 33 \%$ & $\geq 33 \%$ \\
\hline
\end{tabular}

Farming landscapes were classified by the percent of a studies' landscape composed of different sized fields (arable and permanent cropland). These criteria were suitable for all the studies used in our selected reviews, but they do not encompass all combinations of field size. systems which were more difficult to define from satellite imagery. If it was unclear whether a field was pasture or cropland then it was considered cropland.

Many studies defined their location as a single spatial point and in these cases the landscape was considered to be an area within a $1 \mathrm{~km}$ radius of the point. If the location of a study was defined as a general area (for example, "West of Göttingen, Germany"), the study landscape was estimated from the dominant farming system for that area. Where study sites gave high resolution spatial references for multiple sites, the landscape was defined from all the sites. If multiple landscape types were present, the study was included in multiple landscape categories.

To assess economic and biogeographic biases, studies were classified according to national income and global region as per World Bank Databank 2011 data [18], and climate, using ArcMap v10.0 [34] and The Nature Conservancy's terrestrial global ecoregions map [35]. To generate expected values for studies by the World Bank income group, the World Bank region (including all national incomes and not just developing nations), and biome, we assumed that the number of studies in a category would be proportional to the area of cropland contained in that category. FAOSTAT [9] was used to calculate 2011 cropland area (combined area of arable and permanent croplands) for World Bank income groups and regions. Cropland area per biome was extracted from the GlobCover2009 landcover map [36] using The Nature Conservancy's (TNC's) terrestrial ecoregions map [35] in ArcMap V10.0 (ESRI, Redlands, California, USA) [34]. Where crop cover for a pixel was defined by a range, the central value of that range was used. As figures were unavailable to describe the proportion of smallholding area that was cropland, we generated expected values for global and regional areas of smallholder farming (large-scale vs. smallholder only) by assuming that the number of studies in a category would be proportional to the area of agriculture contained in a category. Expected values for the number of studies from different farming landscapes were estimated using the World Census of Agriculture 2000 [17] in conjunction with 2011 FAO national estimates of agricultural area and agricultural population (Additional file 1: Table S1). It should be noted that FAO census data were collected over the period from 1995 to 2005 and for many countries data were deficient or the structural nature of agriculture was poorly assessed (Additional file 1: Table S1). This is an issue that will hopefully be addressed in future censuses and research. Chi-square or exact multinomial goodness-of-fit tests were used to compare observed against expected proportions. Exact multinomial tests used MonteCarlo simulations with one billion trials to generate significance values. Statistical analyses were performed in R 3.0.1 (R Foundation for Statistical Computing, Vienna, Austria) [37]. 


\section{Results}

We analysed seven quantitative reviews (Tables 2 and 3 ) relevant to crop pollination and four relevant to biological control containing a total of 190 studies (Additional file 5: Table S3).

\section{Farming landscape}

Overall, smallholder studies accounted for $12 \%(\mathrm{n}=22)$ of the pooled studies $(7 \%, \mathrm{n}=7$, of biological-control studies and $17 \%, n=15$, of pollination studies; Figure 2D). Both globally and in developing nations the expected proportion of smallholder studies was much higher than observed when considering the agricultural population, but not for the agricultural area (Figures 2D and 3). For both services, there were far fewer smallholder studies than expected, given the size of the agricultural population in each farming landscape. Given the size of the agricultural area, in contrast to the agricultural population, biological control was insufficiently studied but there were approximately as many studies as expected for pollination. Considering individual reviews (Additional file 6: Figure S3, studies within a review, not the overall study pool), the mean ratio of large-scale to smallholder studies for pollination was 5.4 (SD 4.5) and 18.3 (SD 8.4) for biological control. Most (10/11) reviews also differed significantly from expected values for farming landscape when considering agricultural population, but when considering global cropland area no significant differences were apparent.

When considering only smallholder studies, the regional distribution was uneven (based on agricultural area; Figure 3A). Most regions apart from 'Latin America and the Caribbean' had fewer than expected smallholder biological-control studies based on smallholder area or population. Smallholder pollination studies exceeded expectations based on area for 'East Asia and the Pacific' and 'Latin America and the Caribbean' but were lacking for 'sub-Saharan Africa'. Nearly all regions were deficient for smallholder pollination studies when considering the agricultural population, again with the exception of 'Latin America and the Caribbean'.

\section{Regions}

Pooling the constituent studies of the quantitative reviews showed that $86 \%(n=88)$ of the biological-control studies and $55 \%(n=45)$ of the pollination studies came from Western Europe and North America (Figures 4 and 2A). Both percentages were significantly higher than expected compared to the $34 \%$ of global cropland contained within the World Bank Regions that encompassed these areas (Figure 2A). There were no biological-control studies in Africa or continental Asia and fewer pollination studies than expected given that these regions contain approximately half of global cropland with an agricultural population of approximately two billion [18]. For information on the importance of a region to various global statistics (for example, crop production, population, biodiversity and so on) see Additional file 2: Figure S1.

\section{Biome (climate)}

With respect to the area of global cropland, the temperate region contributed double the expected number of pooled studies $(77 \%, \mathrm{n}=78$, for biological control and $58 \%, \mathrm{n}=45$, for pollination; Figure 2C). The number of biological control studies was a quarter of that expected $(11 \%, \mathrm{n}=11)$ and, whilst higher, the number of pollination studies was also less than expected $(27 \%, n=22)$. Mediterranean

Table 2 Quantitative reviews and meta-analyses of pollination and biological control selected for this review

\begin{tabular}{lllll}
\hline & Author & Theme & Total studies* & Agricultural studies \\
\hline Pollination & Ricketts et al. [58] & Distance to natural habitat & 22 & 22 \\
& Winfree et al. [39] & Disturbance & 50 & 27 \\
& Williams et al. [59] & Disturbance & 21 & 11 \\
& Garibaldi et al. [29] & Isolation from natural habitat & 29 & 29 \\
& Garibaldi et al. [53] & Crop pollination by insects & 43 & 43 \\
& Kennedy et al. [50] & Local and landscape effects & 34 & 34 \\
& Shackelford et al. [22] & Local and landscape complexity & 19 & 19 \\
Biological control & Unique studies (n) & Natural enemy diversity & $\mathbf{1 1 5}$ & $\mathbf{8 8}$ \\
& Letourneau et al. [60] & Landscape complexity & 45 & 30 \\
& Chaplin-Kramer et al. [61]** & Landscape complexity & 25 & 44 \\
& Veres et al. [25] & Local and landscape complexity & 28 & $\mathbf{2 3}$ \\
& Shackelford et al. [22] & & $\mathbf{1 3 8}$ & $\mathbf{1 0 2}$
\end{tabular}

*The number of studies we present may differ with those presented by a review as some combined studies from different years at the same location into single entries. These were spilt for the purposes of this review. Other quantitative reviews (QRs) split single studies into multiple entries when more than one crop was investigated. Here we consider them as a single study.

**46 studies were used in this review but one $\mathrm{PhD}$ thesis (O'Rourke, 2010) was omitted due to lack of access. 
Table 3 Significance of developing nations (as classified by the World Bank as low to upper-middle income) to global population and agriculture statistics (for regional information see Additional file 2: Figure S1)

\begin{tabular}{llll}
\hline & World & Developing nations & All other nations \\
\hline Agricultural land (million km²)* & 48 & $74 \%$ & $26 \%$ \\
Cereal production (million metric tons) $^{*}$ & 2,587 & $71 \%$ & $29 \%$ \\
Land under cereal production (million km2)* $^{*}$ & 7.0 & $80 \%$ & $20 \%$ \\
Population (million)* & 6,974 & $84 \%$ & $16 \%$ \\
Agricultural population (million)* & 2,598 & $98 \%$ & $2 \%$ \\
Yield gap (percentage difference between actual and potential & $57 \%$ & $63 \%$ & $38 \%$ \\
crop yields in high input systems)** & & $1 \%$ \\
Agricultural population using holdings <2 ha (million)*** & 2,147 & $15 \%$ & $1 \%$ \\
Smallholdings $<2$ ha as percentage of global agricultural area*** & $16 \%$ & $15 \%$ & \\
\hline
\end{tabular}

*2011 [9,18]. **2000 [56]. ***Values estimated using data from the World Census of Agriculture 2000 [9, 17] (Additional file 1: Table S1).

studies were more numerous than expected from cropland area for both pollination and biological control. Individual reviews on pollination contained studies with the expected proportions (given cropland area) for temperate and tropical biomes, whereas the coverage within three biological-control reviews was significantly and strongly biased towards temperate biomes (Additional file 6:
Figure 3). The remaining biological control review by Letourneau et al. (2009) was also significantly skewed to temperate studies, but much less so, and it did explicitly compare tropical and temperate studies. Overall, nine studies were from biomes that were of low productivity (cold or dry) or small in extent: seven were from deserts and xeric bushlands and two were from boreal and taiga, a

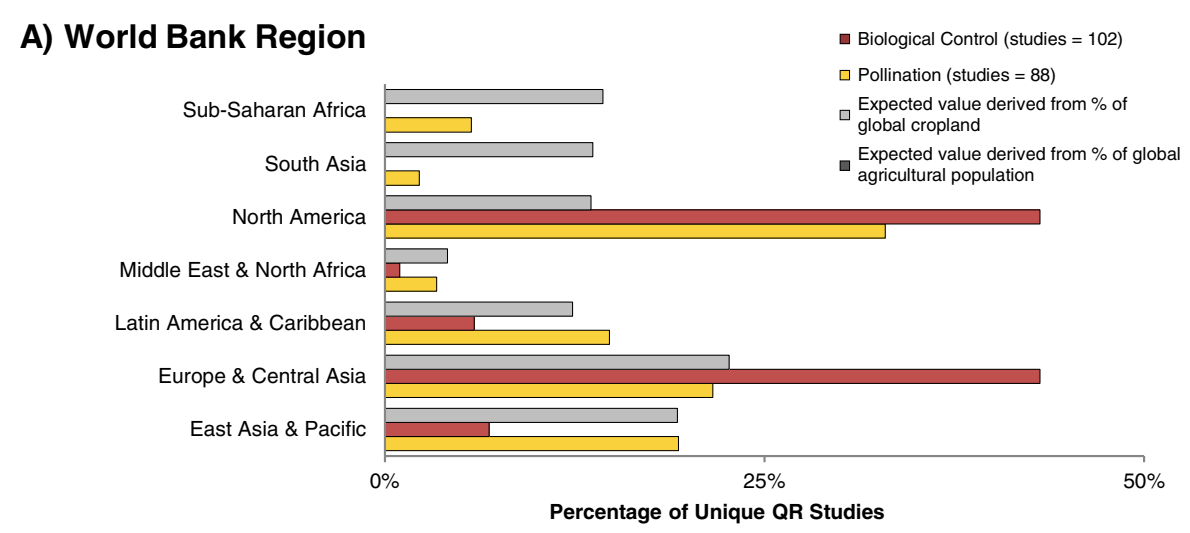

B) Income

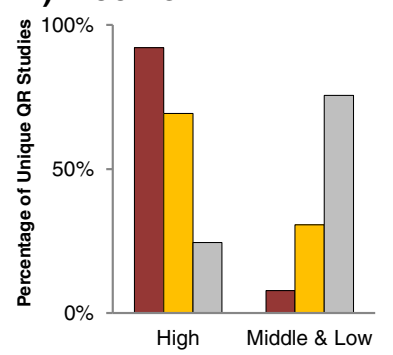

C) Biome

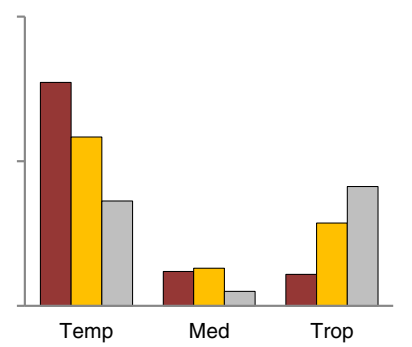

D) Farming System

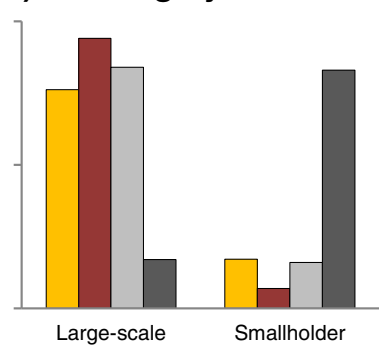

Figure 2 Analyses of pooled studies for biases in region, income group, biome and farming landscape. Unique pollination and biological control studies (relevant to agriculture), pooled from all quantitative reviews, are compared by percentage for World Bank regions (A), World Bank income groups (B), biomes (C) and farming landscapes (D). In C) Trop = tropical and sub-tropical; Temp = temperate; Med = Mediterranean. Expected values for each factor level were derived from the percentage of the total area of global cropland (A and B) [9]; the percentage of the total area of global cropland (C) [35,36]; and the percentage of global agricultural area (D) $[17,18]$ or the percent of the global agricultural population in each farming landscape. A) Region Pollination (Poll): $X^{2}=37.9, P<0.001$; Biocontrol (BioC): $P<0.001$ (Exact Multinomial Test). B) Income Poll: $X^{2}=95.8$; $P<0.001$; BioC: $X^{2}=253.0, P<0.001$. C) Biome Poll: $X^{2}=18.3, P<0.001$; BioC: $X^{2}=78.1, P<0.001$. D) Farming System percent Global Agriculture: Poll: $P=0.541, X^{2}=0.4$; BioC: $P=0.014, X^{2}=6.09$; percent Global Agricultural Population: $P$ oll: $P<0.001, X^{2}=237.5 ;$ BioC: $P<0.001, X^{2}=412.4$ (Note a for tests in $D$ is 0.025 due to a Bonferoni correction for multiple testing). 


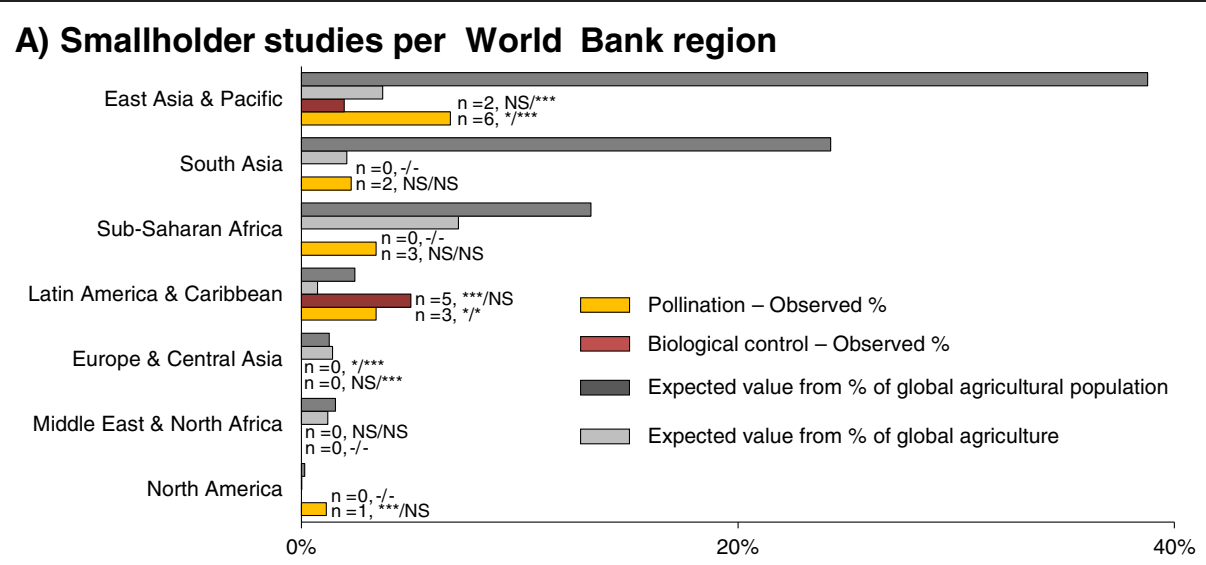

\section{B) Smallholder studies per development class}

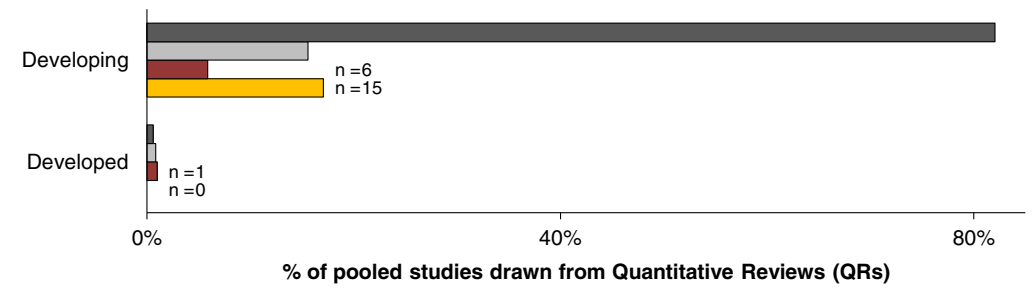

Figure 3 Analysis of only smallholder studies by region and development class. Pollination and biological control studies from smallholder farming landscapes as a percent of all unique pooled studies for each service are compared by $\mathbf{A}$ ) World Bank regions and B) development class. Expected values for $A$ and $B$ were derived from $[9,17]$ and were generated by multiplying the global percent of agricultural land/agricultural population for a region/development class by the within factor percent that was estimated to be smallholder.

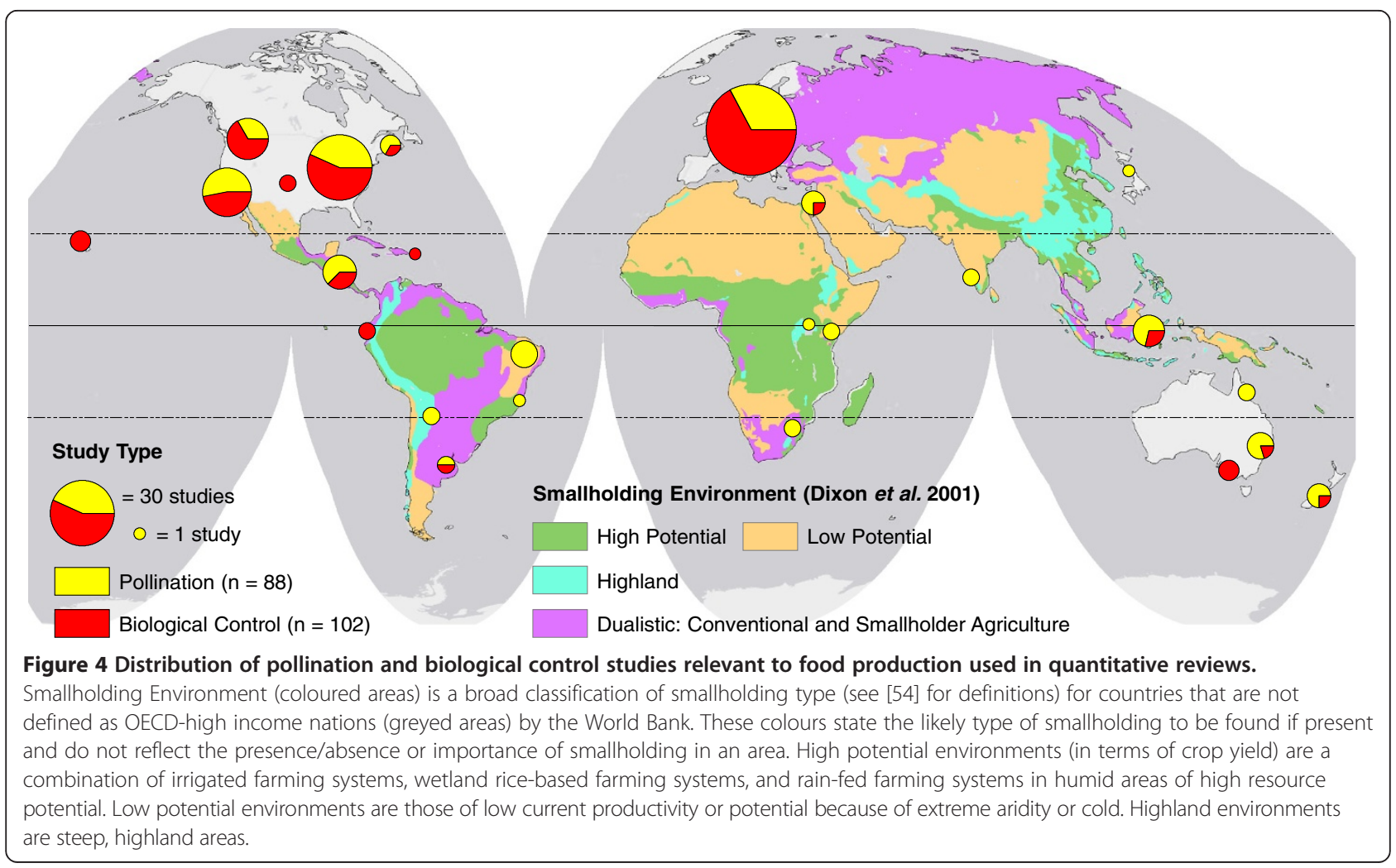


further study was from the montane grasslands and shrublands biome.

\section{Income (development)}

Studies from developed regions accounted for 82\% ( $\mathrm{n}=155)$ of pooled studies $(92 \%, \mathrm{n}=94$, of biological control and $69 \%, \mathrm{n}=61$, of pollination studies; Figure $2 \mathrm{~B}$ ). The number of pooled pollination studies from developing countries was approximately equal to expectations based on cropland area (Figure 3B) although with varied geographic distribution (Figure 3A). However, biological control (pooled) was insufficiently studied in developing countries (Figure 3B). On an individual basis, most reviews (10 out of 11) also had significantly fewer studies than expected from developing regions (Additional file 6: Figure S3).

\section{Discussion}

\section{Food security and sustainable intensification}

Agricultural growth is particularly effective in improving food security, especially in low income areas [38], and sustainable intensification is a pathway for realising this $[2,10,19]$. Sustainable intensification includes enhancing or conserving ecosystem services for the role they can play in maintaining and increasing crop production. This aspect of sustainable intensification is known as "ecological intensification" [21]. Ecological intensification is as important in the developing world as it is in the developed world. Whilst most of our understanding of some ecosystem services - exemplified here by pollination and biological control - comes from the temperate and developed world, the bulk of the world's agricultural land, production and human population can be found in the developing world. In addition, the diversity of farming systems in the developing world is greater than the more uniform largescale and typically intensive agriculture in the developed world. Sustainable intensification of developing world agriculture must include the billions of farmers that are smallholders $[19,38]$ for whom management guidance for ecological intensification must also work [8]. However, we show here that there are significant farming-landscape, regional, climatic and economic biases in the evidence base underpinning the likely contribution of regulating ecosystem services to sustainable intensification via quantitative review.

\section{Farming landscape}

Only $12 \%$ of pooled studies came from smallholder-farmed landscapes as most quantitative reviews were based on data from large-scale farming and typically used three or fewer studies from smallholder-farmed landscapes. The extent to which management interventions derived from research conducted in large-scale farms in developed regions, such as the US and Western Europe, can be generalised to benefit food security in other regions is likely to be limited when there are significant contextual differences in the farming system, climate (for example, differences in extremes and modality of temperature and rainfall between temperate and tropical regions) and biogeography (for example, differences in regional species pools).

Compared to large-scale farming landscapes smallholder-farmed landscapes are much more diverse in terms of local and landscape complexity, management intensity and the interactions between them (Additional file 7 : Figure S4). Smallholder landscapes, particularly in areas of subsistence farming, are likely to have a high richness and diversity of crop types, both spatially and temporally [16]. In smallholding areas typical of sub-Saharan Africa (Figure 1A,D), dwellings and associated livestock, trees, gardens, paths and boundary features generate local complexity, but this is much reduced in large-scale systems. Also, smallholder landscapes typically will not reach the levels of management intensity that occur in large-scale farms. If research efforts are concentrated in large-scale systems then we are unlikely to be fully exploring the gradients of farmland landscape complexity and management intensity and their relationship with ecosystem service providers and function.

As well as differences between smallholder and largescale farmed landscapes, there are clearly cultural and contextual differences within the smallholder system (for example, coffee agroforestry in humid South-East Asia vs. maize farming in semi-arid sub-Saharan Africa). However, of the 22 smallholder studies in the quantitative reviews, 16 came from a single context - coffee systems. Coffee is a cash crop, a perennial crop and a stimulant that has no calorific value. Thus, research in these coffee landscapes is of low relevance to landscapes of annual crops that are grown for local consumption and contribute to local food security. Therefore, we need both an increase in the proportion of smallholder research and also an increase in the diversity of research. All two billion smallholders two billion decision makers - are unlikely to be served by the same research findings. Moreover, since our expectations of how much research should come from smallholder farmed landscapes were based on the number of smallholder farmers, the results were more significantly biased against smallholder farmed landscapes than they were when our expectations were based on the area of smallholder farmland. Although the area of smallholder farmland is more relevant to total global food production, we emphasize that the number of smallholders, who constitute a large proportion of the undernourished, would seem to be more relevant to local food security. Thus, the combination of diversity and food insecurity in smallholder systems means that research biases against these systems are all the more acute. 


\section{Region}

We found that $55 \%$ of pollination and $86 \%$ of biological control studies came from North America and Western Europe. Regional biases such as these might pose a problem for generalising to other under-represented regions. The responses of different bee species to disturbance $[39,40]$ and the applicability of a generalised ES relationship (for example, the relationship between flower visitation and distance from natural habitat) may depend upon the species present in a region. In some cases, functional groups of service-providing species may be absent or substantially different between regions [31]. For example, bumblebees (Bombus spp.) are a well-studied genus of wild pollinator, for which management options have been developed in Europe and North America [41], but they are absent from sub-Saharan Africa [42]. Furthermore, the balance between ecosystem services and dis-services (services that reduce productivity or increase production costs, such as herbivory) flowing from a natural habitat to a nearby farmland may differ between regions. Quantitative reviews have often found that natural habitats benefit ecosystem services, such as pollination in nearby farmland [for example, 32]. However, the species that can move from natural habitats into croplands can fundamentally differ between regions. Proximity to a natural area in subSaharan African and South Asia can expose a farmer to crop-raiding elephants and primates that can reduce crop yields and create human-wildlife conflict. In contrast, in Europe and North America, regions to which research is biased, crop-raiding is a minor problem. When studying the net benefits of natural habitat in certain sub-Saharan African contexts, we might learn that crop raiding (an ecosystem disservice) tends to outweigh the benefits of enhanced pollination and biological control services on farms near natural habitats. The consequences of crop raiding are likely to impact large landholders less than smallholders, as an individual smallholder can easily lose the majority of their harvest to an elephant or troupe of baboons. Although ecosystem dis-services could strongly affect the design of sustainable farming landscapes (for example, crops that are unpalatable to primates might be used to buffer a habitat with many baboons and monkeys), they are poorly considered in the published literature (but see [43]).

\section{Biome (climate)}

Two-thirds of pooled studies came from the temperate region despite tropical croplands occupying a larger area than temperate croplands. Obviously, there are profound climatic differences between biomes that shape the assemblages of pollinators and invertebrate pests and their natural enemies. In general, the effects of climate and climate change on pollinators are much better understood than are effects on other groups of ecosystem-service providers [44], and our analyses reflect this. We show individual quantitative reviews relevant to pollination tend to balance data from tropical and temperate regions whereas biological-control reviews were all significantly and often strongly biased to the temperate zone.

There can be major differences between tropical and temperate biomes in the spatial and temporal availability of resources important for ecosystem-service providers in natural habitats (habitats that may enhance ES in nearby crops). For example, the plant community in aseasonal tropical lowland forests has a continuous pollination period throughout the year compared to just late spring and summer in northern temperate forests [45]. Temperate forests also have higher mean flower longevity and a larger proportion of wind-pollinated plants than aseasonal tropical forests [45]. As the functional significance (flowers providing nectar and pollen) of a forest to pollinators differs between and within biomes, this is likely to be the case for other habitats (including agricultural land), functions (for example, nesting sites) and ecosystem service providers too. As such, interventions for ecological intensification that require manipulating or conserving natural areas in a farming landscape should carefully consider what climate the intervention was derived from and the implications of any functional differences in habitats between derived and target climates (see [44]).

\section{Income (development)}

It is not surprising that more than $80 \%$ of studies were conducted in developed regions since funding for science is higher there. This may also reflect a publication bias in that researchers from developed nations may be more likely to publish their work in English-language peer-reviewed journals. The consequences of the overabundance of studies from temperate regions and largescale landscapes (particularly the U.S. and Germany) were discussed above.

\section{Insights from large-scale studies}

Studies of ecosystem services from large-scale farming landscapes (typically temperate) provide insight into the aspects of an agro-ecosystem that should be conserved when a complex and/or low-intensity system is faced with intensification. For example, local management options are likely to have more positive effects on service providing insects in agricultural landscapes of intermediate complexity [46-48], but less so in small-scale landscapes comprising many other habitats in addition to agricultural fields [39,49-51]. The interaction of local and landscape factors can be important for ES delivery as was the case for flower visitation and production in commercial South African sunflower fields where the enhancement of floral diversity within fields ameliorated the negative effects of isolation from natural habitat 
[52]. Cultural species (dependent on crop habitats) of pollinators and natural enemies might be negatively affected by landscape complexity, whilst ecotone species and dispersers (dependent on non-crop habitats) might be positively affected [22].

The most recent reviews relevant to pollination should be commended for considering complexity at multiple spatial-scales. For example, Garibaldi et al. 2013 [53] and Kennedy et al. 2013 [48] stratify their study selections to incorporate a range of farming-landscapes for meta-analysis making it much easier to generalise their findings to multiple contexts. However, even in recent reviews, smallholding landscapes are not considered explicitly. As such, determining when generalisations can and cannot be applied to a type of smallholder landscapes across multiple regions (and thus climates) should be a priority for ES science.

\section{Conclusions}

Quantitative reviews are essential for modelling and predicting ES provisioning in the design of sustainable farming landscapes, for directing the policies required to adapt our current farming practices and advancing ecosystem service theory. However, the constituent studies of recent reviews relevant to agricultural biological control and, to a lesser extent, pollination, were biased towards large-scale landscapes and/or global biomes (temperate), regions (North America and Western Europe) and national economic statuses (high-income, developed nations). Differences (spatial and temporal) in management intensity and local complexity between smallholder-farmed and large-scale farming landscapes may cause ecosystem service-providing insects to respond differently to disturbance and management interventions. The high local complexity of smallholder-farmed landscapes could promote beneficial species and, consequently, the ES they provide. In this scenario the conservation of ES whilst increasing crop production will be required (we might term this "ecological conservation") compared to large-scale landscapes where ES are diminished and their restoration or replacement is required (ecological intensification). Biogeographic differences between regions in terms of climate and service- and disservice-providing species pools may also present problems for the generalisation of findings and application of ecological intensification. Thus, generalisations from the quantitative reviews included here to smallholder-farmed landscapes and, for biological-control reviews, to tropical landscapes, should be made with caution, especially in regions where little research has been conducted.

More specifically, research bias in reviews affects their general application to informing about sustainable intensification. The large number of pollination and biological control studies from temperate large-scale farming landscapes suggests we are well placed to improve ES and trial ecological intensification there. However, lower data availability from other farming landscapes and/or climates, notably tropical (for biological control reviews) and smallholder, means we may struggle to use current reviews to inform ecological intensification in such data-deficient regions. This problem is greatest in tropical regions with diverse farming landscapes and high agricultural populations, such as South Asia and sub-Saharan Africa, where smallholdings contribute more than a third of the agricultural area (Additional file 1: Table S1). Data deficiency for regions that contribute much of the world's population, crop production and hunger (for example, South Asia, China, Russia and Africa) poses further problems to improving food security with ecological intensification (and ecological conservation).

Investing globally in smallholder research for multiple crops and finding more projects and publications from regions where there is little information (such as China, Russia, South Asia and Africa) is essential. This is especially the case for research relevant to biological control, which appears more biased than pollination-relevant research. To increase their global relevance, quantitative reviews investigating landscape or local effects on ES should consider the coverage of their datasets with regards to region, climate and farming landscape. Following on from this, future empirical studies should target smallholder systems, with quantification of climate and complexity in time and at multiple spatial-scales. Classification of existing studies that do not present landscape information could also provide new data and this is becoming easier. Open-access satellite imagery (for example, Landsat8 or GoogleEarth) and software (R, QGIS, GRASS) now enable post-hoc classification of farming landscapes, and detailed global datasets for biodiversity, food production and development are available from the IUCN, World Bank and FAO. International collaboration is needed to search for, translate (if necessary) and disseminate the ES datasets that no doubt exist in the developing world. We suggest that non-English language publications and agricultural institutions that may often be overlooked will be productive. Data regarding the cost of ecosystem dis-services in agricultural areas near protected areas in South Asia or sub-Saharan Africa may already be available from social and developmental disciplines. If so, this should be integrated into current assessments of the net ES value of natural habitats.

Global datasets regarding the structure of farmland are incomplete and inconsistent. Therefore, our estimates of smallholder area in some regions, such as sub-Saharan Africa, were based on limited data and we hope the pending World Census of Agriculture 2010 will improve the situation. Furthermore, our classification of landscapes into broad structural categories was necessarily 
simplistic. From an ES perspective, smallholding landscapes could better be defined using statistical measures of configuration (see [50]) and information regarding composition and management. An appropriate classification scheme for small-scale farming (perhaps building on [54]) could be used as a guide to ecological intensification/conservation.

In the face of global climate change and challenges to food security, it is important to understand these issues for diverse environmental conditions and landscapes that fully represent the global farming constituency. Further investigation of the conditions that characterize smallholderfarmed landscapes would provide crucial information regarding the resilience of such landscapes to environmental disturbance across multiple ecosystem services.

\section{Availability of supporting data}

See Additional file 1: Table S1 and Additional file 5: Table S3.

\section{Additional files}

Additional file 1: Table S1. Word Census of Agriculture 2000 farm area and population coverage (Table 1) and estimates (Table 2). Methods for estimating the area of smallholder farmland are presented here along with tabulated results.

Additional file 2: Figure S1. Relative significance of agricultural, human population and biodiversity indicators between World Bank Regions. Each factor (represented by a coloured line) is scored by dividing the regional value by the highest value recorded for that factor (maximum score is therefore 1), with the exception of yield gap which is the actual percentage for each region. Factor values were derived as follows: Biodiversity and threats (green sector): $\mathbf{A g l n c}=$ increase in agricultural area for 2001 to 2011 [9]; Forest = area of forested land [1]; En-T = threatened endemic species [2], En-Sp=endemic species [55]. Food production and demand (red sector): YGap = percentage gap between actual and potential production [56]; AgPop=agricultural population [4]; Pop2011 = total population [4]; Pop2050 = predicted 2050 population increase [18]; Crop $=$ area of global cropland [1]. Knowledge (blue sector) was derived from the numbers of studies contributing to quantitative reviews (Figure 2): Poll $=$ studies relevant to pollination; $\mathbf{B i o C}=$ studies relevant to biological control. Farming System (purple sector) bars represent a qualitative estimation of importance to production and livelihoods based on reports $[14,15]$ and the informed opinion of the authors: SH/D = smallholder and dualistic farms and landscapes, $\mathbf{C}=$ large-scalefarms.

Additional file 3: Figure S2. Smallholding land-use scenarios. Complexity is a combination of spatio-temporal compositional and configurational heterogeneity (see [57]). Intensity refers to management intensity including factors such as chemical and inorganic fertiliser inputs, irrigation and mechanisation, lower intensity need not lead to lower yields when sustainable management options are used. Scenarios: AD is high intensity and high local complexity; AC is high intensity and low local complexity (main text Figure 1C); BD is low intensity and high local complexity (main text Figure 1A); and BC: low intensity and low local complexity. Due to 'conventional' agricultural intensification it is probable that of global farms more will fall in the region between $A C$ to $B D$ than $A D$ to $B C$.

Additional file 4: Figure S4. Interaction of local complexity and management intensity between farming landscapes. Here we theoretically compare large-scale farming landscapes (green) to smallholder farming landscapes (red). Points suggest the location of the farming systems shown in Figure 1 (main text) within this space. There is overlap between farming systems, but there is a greater diversity of smallholder-farmed landscapes hence they occupy a much greater area than large-scale landscapes. Configurational heterogeneity (geometry) limits both farming types for local complexity. A relatively small maximum field size for smallholder landscapes puts a lower limit on local complexity and vice-versa for large-scale farms. Limits for both axes are hypothetical and will vary with context.

Additional file 5: Table S3. Studies relative to agriculture included in our analyses. The "Income" column refers to the World Bank Income status for the country or countries a study was conducted in: $\mathrm{H}=\mathrm{High}$ Income; UM = Upper Middle Income; LM = Lower Middle Income; and L = Low Income. High income nations were considered to be developed economies and all other nations developing economies. The "ES" column refers to the ecosystem service a study was relevant to.

Additional file 6: Figure S3. Study ratios for individual quantitative reviews. For each quantitative review included in our analyses we show the ratio of studies (relevant to agriculture) for: 1) Income, high-income nations vs. low- and middle-income nations (derived from World Bank categories); 2) Landscape, large-scale vs. smallholder landscapes; and 3) Biome, temperate regions vs. tropical regions. There were zero smallholder or tropical studies contributing to Veres et al. (2011). Chi-squared (or Exact Multinomial Test when values $<5$ present) significance values were calculated in R 3.0 and are presented by: NS $=P>0.05 ;{ }^{*}=P \leq 0.05$; $*^{*}=P<0.01$; and ${ }^{* *}=P<0.001$. Tests compared observed values with expected values which were derived from: 1) (Income) Estimates of the percent of the 2012 global arable and permanent cropland [9]; 2) (Landscape) Estimate of total farming system area [2] converted into a percent of 2012 global arable and permanent cropland area [1] (left value) and estimate of the percent of global number farms that were in each class [16] (right value); and 3) (Biome) percent of global cropland [36].

Additional file 7: Table S2. Excluded quantitative reviews.

\section{Abbreviation}

ES: Ecosystem service.

\section{Competing interests}

The authors declare that they have no competing interests.

\section{Authors' contributions}

PRS was responsible for the conception and design of the study. PRS, TGB, GS, LGC, LAG and SMS were involved in interpretation of results and drafting the manuscript. PRS acquired the data, carried out the analysis, and coordinated the manuscript. All authors read and approved the final manuscript.

\section{Acknowledgements}

PRS is supported by a BBSRC doctoral training grant.

\section{Author details}

${ }^{1}$ Africa College and School of Biology, University of Leeds, Leeds LS2 9JT, UK. ${ }^{2}$ Naturalis Biodiversity Center, P.O. Box 9517, Leiden 2300RA, The Netherlands. ${ }^{3}$ Sede Andina, Universidad Nacional de Río Negro (UNRN) and Consejo Nacional de Investigaciones Científicas y Técnicas (CONICET), Mitre 630, San Carlos de Bariloche, CP 8400, Río Negro, Argentina.

Received: 4 December 2013 Accepted: 21 February 2014 Published: 19 March 2014

\section{References}

1. Foresight: The Future of Food and Farming. London: The Government Office for Science; 2011.

2. The Royal Society: Reaping the Benefits: Science and the Sustainable Intensification of Global Agriculture. London: The Royal Society; 2009.

3. Bruinsma J: The resource outlook to 2050. In Expert Meeting on How to Feed the World in 2050, Proceedings of the Expert Meeting on How to Feed the World in 2050 24-26 June 2009, FAO Headquarters, Rome. Rome: FAO; 2009.

4. Godfray HC, Beddington JR, Crute IR, Haddad L, Lawrence D, Muir JF, Pretty J, Robinson S, Thomas SM, Toulmin C: Food security: the challenge of feeding 9 billion people. Science 2010, 327:812-818.

5. De Schutter O: Promotion and Protection of All Human Rights, Civil, Political, Economic, Social and Cultural Rights, Including the Right to 
Development: Report of the Special Rapporteur on the Right to Food Olivier De Schutter. In Promotion and Protection of All Human Rights, Civil, Political, Economic, Social and Cultural Rights, Including the Right to Development: Report of the Special Rapporteur on the Right to Food, Olivier De Schutter. Geneva, Switzerland: United Nations General Assembly; 2008

6. Alexandratos N, Bruinsma J: World Agriculture towards 2030/2050: the 2012 revision. In ESA Working Paper No. 12-03. Rome: FAO; 2012.

7. FAO: FAO Statistical Yearbook 2013: World Food and Agriculture. Rome: FAO; 2013.

8. Dobie P, Yuksel N: Halving Hunger: it Can Be Done. London: Earthscan; 2005.

9. FAOSTAT. [http://faostat3.fao.org/home/index.html].

10. Pretty J: Agricultural sustainability: concepts, principles and evidence. Phil Trans R Soc B 2008, 363:447-465.

11. Millennium Ecosystem Assessment: Ecosystems and Human Well-Being Washington DC: Island Press; 2005.

12. Bacon CM, Getz C, Kraus S, Montenegro M, Holland K, Bacon CM, Getz C, Kraus S, Montenegro M, Holland $\mathrm{K}$ : The social dimensions of sustainability and change in diversified farming systems. Synthesis, part of a Special Feature on A Social-Ecological Analysis of Diversified Farming Systems: Benefits, Costs, Obstacles, and Enabling Policy Frameworks. Eco/ Soc 2012, 17:41.

13. Kremen C, Miles A: Ecosystem services in biologically diversified versus conventional farming systems: benefits, externalities, and trade-offs. Ecol Soc 2012, 17:40.

14. Salami A, Karama A, Brixiova Z: Working Paper 105: Smallholder Agriculture in East Africa: Trends Constraints and Opportunities. Tunis, Tunisia: African Development Bank; 2010

15. Singh R, Kumar P, Woodhead T: Smallholder Farmers in India: Food Security and Agricultural Policy. Bangkok, Thailand: FAO; 2002.

16. IFAD, UNEP: Smallholders, Food Security, and the Environment. Rome: IFAD; 2013.

17. FAO: World Census of Agriculture: Main Results and Metadata by Country (1996-2005). Rome: FAO; 2000:2010.

18. World Bank Databank. [http://databank.worldbank.org]

19. The Montpellier Panel: Sustainable Intensification: a New Paradigm for African Agriculture. London: The Montepellier Panel; 2013.

20. IFAD: Rural Poverty Report 2011: New Realities, New Challenges, New Opportunities for Tomorrow's Generation. Rome: IFAD; 2011.

21. Bommarco R, Kleijn D, Potts SG: Ecological intensification: harnessing ecosystem services for food security. TREE 2013, 28:230-238.

22. Shackelford G, Steward PR, Benton TG, Kunin WE, Potts SG, Biesmeijer JC, Sait SM: Comparison of pollinators and natural enemies: a meta-analysis of landscape and local effects on abundance and richness in crops. Biol Rev 2013, 88:1002-1021.

23. Pontin DR, Wade MR, Kehrli P, Wratten SD: Attractiveness of single and multiple species flower patches to beneficial insects in agroecosystems Ann Appl Biol 2006, 148:39-47.

24. Krewenka KM, Holzschuh A, Tscharntke T, Dormann CF: Landscape elements as potential barriers and corridors for bees, wasps and parasitoids. Biol Conserv 2011, 144:1816-1825.

25. Veres A, Petit S, Conord C, Lavigne C: Does landscape composition affect pest abundance and their control by natural enemies? A review. Agr Ecosyst Environ 2013, 166:110-117.

26. Winfree $R$, Kremen $C$ : Are ecosystem services stabilized by differences among species? A test using crop pollination. Proc Bio/ Sci 2009, 276:229-237.

27. Tscharntke T, Batáry P, Dormann CF: Set-aside management: how do succession, sowing patterns and landscape context affect biodiversity? Agr Ecosyst Environ 2011, 143:37-44.

28. Diekotter T, Wamser S, Wolters V, Birkhofer K: Landscape and management effects on structure and function of soil arthropod communities in winter wheat. Agr Ecosyst Environ 2010, 137:108-112.

29. Garibaldi LA, Steffan-Dewenter I, Kremen C, Morales JM, Bommarco R, Cunningham SA, Carvalheiro LG, Chacoff NP, Dudenhöffer JH, Greenleaf SS, Holzschuh A, Isaacs R, Krewenka K, Mandelik Y, Mayfield MM, Morandin LA, Potts SC, Ricketts TH, Szentgyörgyi H, Viana BF, Westphal C, Winfree R, Klein AM: Stability of pollination services decreases with isolation from natural areas despite honey bee visits. Ecol Lett 2011, 14:1062-1072

30. Kareiva P, Tallis H, Ricketts TH, Daily GC, Polasky S: Natural Capital: Theory and Practice of Mapping Ecosystem Services. Oxford: Oxford University Press; 2011.
31. Archer C, Pirk C, Carvalheiro L, Nicolson S: Economic and ecological implications of geographic bias in pollinator ecology in the light of pollinator declines. Oikos. In press.

32. Bing maps. [http://www.bing.com/maps/]

33. Google maps. [https://maps.google.com/]

34. ESRI: ArcGIS Desktop. Release 10. Redlands, CA: ESRI; 2011.

35. The Nature Conservancy: Global Ecoregions, Major Habitat Types, Biogeographical Realms and the Nature Conservancy Terrestrial Assessment Units as of December 14, 2009. Vienna, Austria: The Nature Conservancy; 2009.

36. Arino O, Ramos J, Kalogirou V, Defourny P, GlobCover AF: ESA Living Planet Symposium 2009. Bergen, Norway: European Space Agency; 2010.

37. R Development Core Team: R: A Language and Environment for Statistical Computing. Vienna, Austria: R Foundation for Statistical Computing; 2013 [http://web.mit.edu/r_v3.0.1/fullrefman.pdf]

38. McGuire S: The State of Food Insecurity in the World 2012. Economic growth is necessary but not sufficient to accelerate reduction of hunger and malnutrition. Adv Nutr 2013, 4:126-127.

39. Winfree $R$, Aguilar $R$, Vazquez DP, LeBuhn G, Aizen MA: A meta-analysis of bees' responses to anthropogenic disturbance. Ecology 2009, 90:2068-2076.

40. Cariveau DP, Williams NM, Benjamin FE, Winfree R: Response diversity to land use occurs but does not consistently stabilise ecosystem services provided by native pollinators. Ecol Lett 2013, 19:835-950.

41. Dicks LV, Showler DA, Sutherland WJ: Bee conservation: evidence for the effects of interventions. In Synopses of Conservation Evidence. Exeter, UK: Pegasus Publishing; 2010.

42. Michener CD: The Bees of the World 2nd Edition. Baltimore, MD: Johns Hopkins University Press; 2000.

43. Zhang W, Ricketts TH, Kremen C, Carney K, Swinton SM: Ecosystem services and dis-services to agriculture. Ecol Econ 2007, 64:253-260.

44. Cock MJ, Biesmeijer JC, Cannon RJ, Gerard PJ, Gillespie D, Jimenez JJ, Lavelle PM, Raina SK: The implications of climate change for positive contributions of invertebrates to world agriculture. CAB Rev 2013, 8:1-48.

45. Bawa KS: Plant-pollinator interactions in tropical rain forests. Annu Rev Ecol Syst 1990, 21:399-422

46. Tscharntke T, Klein AM, Kruess A, Steffan-Dewenter I, Thies C: Landscape perspectives on agricultural intensification and biodiversity - ecosystem service management. Ecol Lett 2005, 8:857-874.

47. Tscharntke T, Tylianakis JM, Rand TA, Didham RK, Fahrig L, Batary P, Bengtsson J, Clough Y, Crist TO, Dormann CF, Ewers RM, Fründ J, Holt RD, Holzschuh A, Klein AM, Kleijn D, Kremen C, Landis DA, Laurance W, Lindenmayer D, Scherber C, Sodhi N, Steffan-Dewenter I, Thies C, van der Putten $\mathrm{WH}$, Westphal C: Landscape moderation of biodiversity patterns and processes - eight hypotheses. Biol Rev Camb Philos Soc 2012, 87:661-685

48. Scheper J, Holzschuh A, Kuussaari M, Potts SG, Rundlöf M, Smith HG, Kleijn D: Environmental factors driving the effectiveness of European agri-environmental measures in mitigating pollinator loss - a meta-analysis. Ecol Lett 2013, 16:912-920.

49. Bengtsson J, Ahnstrom J, Weibull AC: The effects of organic agriculture on biodiversity and abundance: a meta-analysis. Appl Ecol J 2005, 42:261-269.

50. Kennedy CM, Lonsdorf E, Neel MC, Williams NM, Ricketts TH, Winfree R, Bommarco R, Brittain C, Burley AL, Cariveau D, Carvalheiro LG, Chacoff NP, Cunningham SA, Danforth BN, Dudenhöffer JH, Elle E, Gaines HR, Garibaldi LA, Gratton C, Holzschuh A, Isaacs R, Javorek SK, Jha S, Klein AM, Krewenka K, Mandelik Y, Mayfield MM, Morandin L, Neame LA, Otieno M, et al: A global quantitative synthesis of local and landscape effects on wild bee pollinators in agroecosystems. Ecol Lett 2013, 16:584-599.

51. Batáry P, Báldi A, Kleijn D, Tscharntke T: Landscape-moderated biodiversity effects of agri-environmental management: a meta-analysis. Proc Biol Sci 2011, 278:1894-1902.

52. Carvalheiro LG, Veldtman R, Shenkute AG, Tesfay GB, Pirk CW, Donaldson JS, Nicolson SW: Natural and within-farmland biodiversity enhances crop productivity. Ecol Lett 2011, 14:251-259.

53. Garibaldi LA, Steffan-Dewenter I, Winfree R, Aizen MA, Bommarco R, Cunningham SA, Kremen C, Carvalheiro LG, Harder LD, Afik O, Bartomeus I, Benjamin F, Boreux V, Cariveau D, Chacoff NP, Dudenhöffer JH, Freitas BM, Ghazoul J, Greenleaf S, Hipólito J, Holzschuh A, Howlett B, Isaacs R, Javorek SK, Kennedy CM, Krewenka KM, Krishnan S, Mandelik Y, Mayfield MM, 
Motzke I, et al: Wild pollinators enhance fruit set of crops regardless of honey bee abundance. Science 2013, 339:1608-1611.

54. Dixon JA, Gibbon DP, Gulliver A: Farming Systems and Poverty: Improving farmers' Livelihoods in a Changing World. Rome: FAO; 2001.

55. IUCN Redlist. [www.iucnredlist.org/]

56. FAO/IIASA: Global Agro-Ecological Zones (GAEZ v3.0). Laxenburg, Austria: IIASA and Rome: FAO; 2012.

57. Fahrig L, Baudry J, Brotons L, Burel FG, Crist TO, Fuller RJ, Sirami C, Siriwardena GM, Martin J-L: Functional landscape heterogeneity and animal biodiversity in agricultural landscapes. Ecol Lett 2011, 14:101-112.

58. Ricketts TH, Regetz J, Steffan-Dewenter I, Cunningham SA, Kremen C, Bogdanski A, Gemmill-Herren B, Greenleaf SS, Klein AM, Mayfield MM, Morandin LA, Ochieng' A, Potts SG, Viana BF: Landscape effects on crop pollination services: are there general patterns? Ecol Lett 2008, 11:499-515. Erratum in: Ecol Lett 2008, 11:1121. Potts, Simon G [added].

59. Williams NM, Crone EE, Roulston TH, Minckley RL, Packer L, Potts SG: Ecological and life-history traits predict bee species responses to environmental disturbances. Biol Conserv 2010, 143:2280-2291.

60. Letourneau DK, Jedlicka JA, Bothwell SG, Moreno CR: Effects of natural enemy biodiversity on the suppression of arthropod herbivores in terrestrial ecosystems. Annu Rev Ecol Syst 2009, 40:573-592.

61. Chaplin-Kramer R, O'Rourke ME, Blitzer EJ, Kremen C: A meta-analysis of crop pest and natural enemy response to landscape complexity. Ecol Lett 2011, 14:922-932.

doi:10.1186/2048-7010-3-5

Cite this article as: Steward et al: Pollination and biological control research: are we neglecting two billion smallholders. Agriculture \& Food Security 2014 3:5.

\section{Submit your next manuscript to BioMed Central and take full advantage of:}

- Convenient online submission

- Thorough peer review

- No space constraints or color figure charges

- Immediate publication on acceptance

- Inclusion in PubMed, CAS, Scopus and Google Scholar

- Research which is freely available for redistribution 